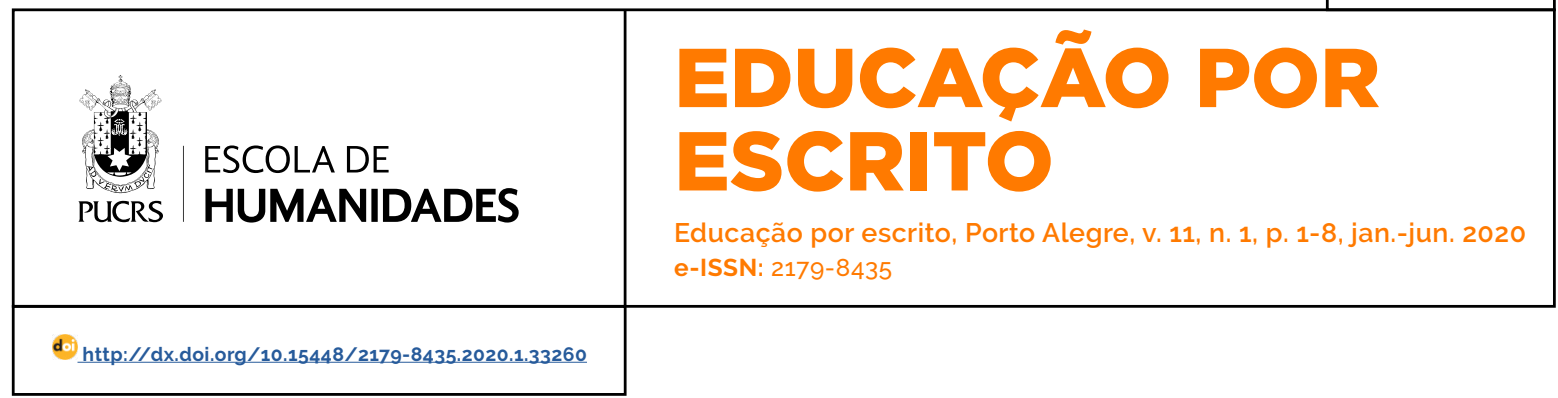

SEÇÃO ARTIGOS

\title{
Uma análise das permanências e das rupturas em duas políticas de ampliação da jornada escolar brasileiras: CIACs e PME
}

\author{
An analysis of permanences and ruptures in two educational policies for expanding \\ Brazilian school day: CIACs and PME
}

\section{Carlos Antonio Diniz Junior ${ }^{1}$ \\ orcid.org/0000-0002-4420-3403 junior.diniz.jd@gmail.com}

Recebido em: 4 fev. 2019. Aprovado em: 8 jan. 2020. Publicado em: 27 jul. 2020.
Resumo: Este trabalho tem como objetivo analisar as permanências e as rupturas existentes em duas políticas de ampliação da jornada escolar no Brasil, implementadas no período de 1991 a 2015, quais sejam os Centros Integrados de Apoio à Criança (CIACs) e o Programa Mais Educação (PME). Tendo por referência metodológica a análise documental dos textos editados por essas políticas, pode-se destacar que, tanto os CIACs como o PME se constituíram sob a égide da atuação de diversos atores sociais em suas ações bem como da focalização do público atendido - população em situação de vulnerabilidade social - sob a perspectiva da proteção social. Aponta-se, também, que, diferentemente do que ocorreu no PME, os CIACs previam um investimento de recursos para a construção de espaços físicos para a sua implementação. O espaço físico a ser utilizado igualmente se altera nas duas políticas, sendo que a primeira (CIACs) tem a centralidade na escola e, no caso do PME, a utilização de outros espaços é incentivada para a garantia das ações. Destaca-se, ainda, a influência dos textos editados por organismos internacionais para a elaboração e o modus operandi das duas políticas.

Palavras-chave: Politica educacional. Educação em tempo integral. Centro Integrado de Apoio à Criança. Programa Mais Educação.

Abstract: This paper aims to analyze the continuities and ruptures existing in two policies for expansion of the school day in Brazil, implemented from 1991 to 2015, namely the Integrated Centers for Child Care (CIACs) and the More Education Program (PME). Having as a methodological reference the documentary analysis of the texts edited by these policies, both CIACs and PME were constituted under the action of several social actors in their actions, as well as under the targeting of the attended public - population in situation of social vulnerability - from the perspective of social protection. Unlike what happened in the PME, CIACs predicted investment of resources for the construction of physical spaces for its own implementation. The physical space to be used also changed in the two policies, the first one (CIACs) having the centrality in the school and, in the case of the PME, the use of others is encouraged to guarantee the actions. The influence of texts edited by international organizations is also highlighted for the elaboration and modus operandi of the two policies.

Keywords: Educational policy. Full-time Education. Integrated Centers for Child Care. More Education Program.

\section{Introdução}

Este artigo analisa duas políticas de ampliação da jornada escolar na perspectiva do tempo integral implementadas no Brasil, no âmbito do governo federal, no período de 1990 até o ano de 2015. Destaca-se que nesse espaço de tempo três (03) políticas com esse foco foram concretizadas pela União, quais sejam: o Projeto Minha Gente, através 
dos Centros Integrados de Atenção à Criança (CIACs); o Programa Nacional de Atenção à Criança e ao Adolescente (PRONAICA), por meio dos Centros de Atenção Integral à Criança e ao Adolescente (CAICs) e o Programa Mais Educação (PME). A análise aqui apresentada se refere à primeira (CIACs) e à última política (PME), pois, conforme evidencia Pena (2015) a alteração de CIAC para CAIC foi uma mudança de cunho meramente formal, mantendo-se assim, a lógica da organização do primeiro projeto.

No ano de 1991, por meio de decreto presidencial $^{2}$, foi criado o Projeto Minha Gente, objetivando "desenvolver ações integradas de educação, saúde, assistência e promoção social, relativas à criança e ao adolescente" (BRASIL, 1991, Art. 1. ${ }^{\circ}$. Conforme destacado por Gadotti (2009), os CIACs foram inspirados na experiência dos Centros Integrados de Educação Pública (CIEPs) implementados no governo de Leonel Brizola, no Rio de Janeiro, à época de sua primeira gestão como governador (1983-1987).

O projeto previa a construção de equipamentos próprios, com desenho arquitetônico pré-definido, incluindo salas de aula, alojamento, espaço para atendimento médico e odontológico, salas e espaços para atividades esportivas, culturais e artísticas, além de lavanderia e outros espaços administrativos (BRASIL, 1992). De acordo com o Governo Federal, os CIACs se constituiriam como espaços que garantiriam os direitos de crianças e de adolescentes, expressos na Constituição Federal (CF,1998) e no Estatuto da Criança e do Adolescente $(E C A, 1990)$, de modo a englobar a educação escolar, a cultura, a saúde, o esporte, a creche e a educação para o trabalho (BRASIL, 1992).

Até o final do governo Collor, o projeto previa a construção de 5 mil unidades de CIACs no território brasileiro e, ainda, para o ano de 1991, 20 unidades estavam planejadas para serem inauguradas (PENA, 2015). De acordo com Gadotti (2009, p. 27), o projeto dos CIACs recebeu diversas críticas por estar mais próximo de uma perspectiva "promocional" dos problemas educacionais do que de constituir-se como uma ação pedagógica efetiva.

No ano de 1993, o Projeto Minha Gente foi substituído pelo Programa Nacional de Atenção Integral à Criança e ao Adolescente (Pronaica). Assim como o projeto que o sucedeu, o Pronaica objetivava $o$ atendimento integral a crianças e a adolescentes, por meio de ações articuladas entre os setores públicos e a sociedade civil leia-se: organizações não governamentais -, também na perspectiva da focalização de um determinado público (SOBRINHO; PARENTE, 1995) a ser atendido nos Centros de Atenção Integral à Criança e ao Adolescente (CAICs). De 1991, ano de instituição do Projeto Minha Gente, a 1996, ano de término do Pronaica, foram construidas aproximadamente 500 unidades de CIACs/CAICs no território nacional (PENA, 2015), números esses bem abaixo daquele previsto à época do lançamento dessas ações.

Mais de 10 anos $^{3}$ após o encerramento do Pronaica, no ano de 2007, foi criado o Programa Mais Educação (PME), instituido pela Portaria Interministerial n. 17/2007 (BRASIL, 2007) e regulamentado pelo Decreto $n .{ }^{\circ} 7.083 / 2010$ (BRASIL, 2010). De abrangência nacional, o programa teve por finalidade "contribuir para a melhoria da aprendizagem por meio da ampliação do tempo de permanência de crianças, adolescentes e jovens matriculados em escola pública, mediante oferta de educação básica em tempo integral" (BRASIL, 2010, Art. 1. '). Por seu caráter intersetorial, evidenciado já na portaria que o instituiu, o PME congregou vários atores de diversos setores das políticas públicas e da sociedade civil.

O PME chegou às escolas tendo como um dos objetivos o incentivo para que os entes federados pudessem elaborar e implementar suas politicas locais de educação básica em tempo integral (BRASIL, 2010a), sendo que, com base nos dados publicados no site oficial do MEC, no ano de 2013 o programa se fazia presente em $86,9 \%$ dos municipios brasileiros.

Esse programa esteve alicerçado em um modelo que se pode denominar como de alunos

\footnotetext{
Presidente Fernando Collor de Melo que, no ano de 1992, foi deposto por crime de responsabilidade.

Cabe destacar que nesse periodo (1996 a 2007) ocorreram experiências locais - no âmbito de estados e municipios - para a ampliação da jornada escolar e do atendimento em tempo integral, em consonância com Art. 33 da Ldben (BRASIL, 1996).
} 
em tempo integral (CAVALIERE, 2009), no qual a ampliação da jornada escolar é realizada dentro e/ou fora da escola, de modo que os estudantes estejam sob a responsabilidade dessa instituição, através de parcerias e apoios externos, sejam de outros setores públicos e/ou organizações não governamentais. A seleção das escolas a serem contempladas pelo programa estava relacionada a critérios como a localização em áreas de vulnerabilidade social e baixo Índice de Desenvolvimento da Educação Básica (IDEB), o que aponta para o caráter focalizado e não universalizante das ações do programa.

Partindo dessas politicas objetiva-se, neste trabalho, analisar as permanências e as rupturas existentes entre elas. Trata-se como permanência os elementos que podem ser observados nas duas políticas, levando em consideração as possiveis complementações em decorrência do distanciamento temporal. Por rupturas, destacamse os elementos presentes nos CIACs e que não podem ser notados na experiência do PME. O estudo documental (CELLARD, 2008) se concentrou na análise dos conceitos-chave dos textos dessas políticas (BRASIL, 1991, 1992, 2007, 2010).

Este artigo está organizado em quatro partes, incluindo essa introdução. Na segunda seção são apresentadas reflexões acerca da ampliação da jornada escolar no Brasil e na América Latina, destacando a influência de organismos internacionais na elaboração de politicas e de ações de alargamento da jornada destinada à educação escolar. A terceira seção traz a análise dos resultados do estudo apontando: (1) as permanências nas duas politicas; e (2) as rupturas entre o que foi observado no PME em relação aos CIACs. Por fim, são apresentadas as considerações finais deste trabalho.

\section{A ampliação da jornada escolar: tendências e influências ${ }^{4}$}

A ampliação da jornada escolar de estudantes da educação básica na América Latina e, por conseguinte, no Brasil, é tema de diversos debates, como apontado por Fanfani (2010), Coelho (2012) e Silva (2017), seja no meio acadêmico ou por parte daqueles que se propõem elaboradores de políticas e de ações. Especialmente no âmbito brasileiro, Cavaliere (2007) aponta que, a partir da abertura democrática do País na década de 1980, e com a promulgação da Lei de Diretrizes e Bases da Educação Nacional (Ldben) (BRASIL, 1996), as ações para a ampliação do tempo de permanência dos estudantes nas escolas foram sendo intensificadas.

Esse cenário vivenciado no Brasil pode ser observado também em outros países da América Latina, que engendraram esforços para a ampliação da jornada escolar dos estudantes. Ao refletir sobre essa questão, Silva (2017) aponta que textos editados por organizamos internacionais, em especial o Marco de Ação de Dakar (UNESCO, 2000), influenciaram a elaboração dessas políticas de alargamento do tempo escolar, sob a égide da proteção social e com o objetivo de alcançar melhorias na qualidade da educação nos países latino-americanos.

Anterior a esse periodo, outros documentos editados por organismos internacionais também influenciaram, como afirmam Gentili (1996) e Candau (2013), políticas e reformas educacionais nos paises desse subcontinente. Esses textos (UNESCO, 1990; CEPAL; UNESCO, 1996; BANCO MUNDIAL, 1999) apontavam para a necessidade da diminuição das desigualdades educacionais, para a questão da qualidade e do desempenho escolar e, ainda, para a necessidade de priorização de ações tendo como foco estudantes em situação de vulnerabilidade, na perspectiva da escola se constituir como espaço de proteção social.

Esse discurso de melhoria da qualidade da educação vem acompanhado, nestes textos, da necessidade de descentralização das ações, da introdução de mecanismos de acompanhamento e de avaliação dos resultados e, ainda, da responsabilidade de "todos", para que fossem consolidadas as mudanças necessárias à educação (SHIROMA et al., 2011). Se, por um lado, esse discurso de uma maior participação - há que se

4 Utilização do termo na perspectiva do contexto da influência (BOWE; BALL, 1992; BALL, 1944). O contexto da influência é o lugar da disputa pela elaboração das políticas, espaço no qual os organizamos internacionais exercem seu poder de orientar politicas dos estados-nação. 
questionar sob qual perspectiva - ganha destaque, emerge também uma concepção de que o papel do Estado, no que tange às suas competências de gestão e de financiamento, sejam diminuidas (ABICALIL, 2001), uma vez que esse não possui o modus operandi da gestão do mercado.

Ainda no rol dessas orientações, esses organismos apontavam a ampliação da jornada escolar como uma estratégia que viria ao encontro da diminuição da desigualdade, e como alternativa para a melhoria da qualidade educacional (DINIZ JÚNIOR, 2017). Nesse sentido, em relação a tais políticas, a escola passa a exercer o papel de espaço de mitigação das desigualdades sociais o que, nas palavras de Libâneo (2016), contribui para o enfraquecimento do espaço escolar, uma vez que as propostas contemporâneas 5 de educação integral, utilizadas como recurso discursivo para a ampliação do tempo escolar, estipulam que "a escola faça tudo o que os demais setores não fazem" (LIBÂNEO, 2016, p. 54), de modo a compensar a carência daqueles que estão em situação de negação de direitos, "numa esperada sociedade educativa harmonizada" (2016, p. 54)

De tal modo, as políticas de ampliação da jornada escolar se configuram a partir dessas questões: a necessidade (e a urgência) do atendimento aos sujeitos em situação de vulnerabilidade, o debate sobre o real papel da escola e as concepções (e as disputas) de projeto de sociedade.

\section{CIACs e PME: permanências e rupturas}

Conforme já anunciado, nesta seção serão apresentados os resultados deste estudo. Destaca-se que as duas politicas se constituem sob a égide da atuação de diversos atores sociais em suas ações e a focalização do público atendido sob a perspectiva da proteção social. Entre as rupturas, observa-se a inexistência de recurso financeiro para a construção de escolas para o PME, bem como a mudança na perspectiva do atendimento dos estudantes no tempo integral.

O primeiro elemento a ser assinalado está relacionado à ideia de que a educação é um espaço de todos e não apenas para todos. Tanto nos CIACs como no PME essa prerrogativa está em evidência, de modo que seus textos (BRASIL, 1991, 1992, 2007, 2010) apontam a necessidade de uma ampla articulação entre o Estado, entidades privadas sem fins lucrativos e organizações comunitárias para a efetivação das ações. Essa perspectiva encontra sustentação, no âmbito das legislações brasileiras, na CF de 1998 e na Ldben de1996. Em ambos documentos, é determinada a responsabilidade do Estado, da família e da sociedade na educação da população brasileira.

Essa ideia da responsabilidade de todos também pode ser observada em alguns documentos editados por organismos internacionais, a exemplo da obra Educación y conocimiento: eje de la transformación productiva con equidad (CEPAL; UNESCO, 1996). Nessa publicação, é possivel identificar o apelo à sociedade, no sentido de construir uma educação que se constitua chave para a transformação produtiva e social de países em desenvolvimento, em especial, os latino-americanos (DINIZ JÚNIOR, 2017). De tal modo, pode-se perceber que a perspectiva relacionada ao primeiro elemento aqui destacado possui grande influência dos documentos editados por esses organismos. Tal afirmação vem ao encontro do que é destacado por Shiroma et al. (2011) de que as reformas educacionais e as ações advindas das leituras e das interpretações desses textos internacionais estão sendo cuidadosamente planejadas por esses organismos e anunciadas através de suas repetidas e insistentes recomendações.

A lógica de um esforço coletivo em favor da educação abre um grande espaço para o crescimento da ideia de inserção dos administradores do mercado econômico na definição e no direcionamento das políticas educacionais (FREITAS, 2016). Essa lógica, de

\footnotetext{
5 De acordo com Coelho (2009) concepção de educação em tempo integral na perspectiva sócio-histórica destaca a formação humana em suas múltiplas possibilidades de desenvolvimento, já na perspectiva contemporânea há uma focalização na proteção integral a crianças e adolescentes, na qual a escola assume esse papel.
} 
acordo com Martins (2016), redefine a relação entre o Estado e a sociedade civil, que passa a ser mediada pelo mercado e sua perspectiva econômica neoliberal.

De tal modo, pode-se dizer que, muito mais que garantir a educação dos sujeitos, essa relação sustenta, reforça e alimenta uma perspectiva mercantilista da educação, articulando uma relação orgânica e convincente entre o processo educacional, visto como um direito da cidadania e da competitividade (COUTINHO, 1994). De tal modo, a concepção de educação que fundamenta essas ações se pauta em uma lógica de mercado, na qual não estamos falando apenas de direito à educação, mas dessa como um produto e como um mecanismo de permanência do capitalismo e das suas desigualdades.

Outro elemento a ser destacado, está relacionado à focalização do atendimento. Nas duas políticas - CIACs e PME -, em consonância com documentos publicados por organismos internacionais (UNESCO, 1990; CEPAL; UNESCO, 1996; BANCO MUNDIAL, 1999), está presente a priorização do atendimento às crianças e os adolescentes em situação de vulnerabilidade social. Especificamente em relação a esse ponto, podemos considerar, conforme evidenciado por Menezes (2008) ao refletir sobre o PME, que a priorização de crianças "das camadas mais necessitadas" poderia ser considerada como uma ação que não atenta para o princípio constitucional de que somos todos iguais perante a lei. Por outra óptica, essa focalização poderia ser considerada como uma ação do poder público no sentido de buscar diminuir as desigualdades sociais e de oportunidades, tão presentes em nosso Pais (DINIZ JÚNIOR, 2017).

Destaca-se aqui que não se pretender aprofundar o debate acima, uma vez que a questão central a ser refletida está na real intenção associada a essa focalização. Em primeiro lugar, não por uma questão de importância, deve-se refletir sobre qual democracia está presente no Estado brasileiro. De acordo com Boron (2003), uma democracia deve se caracterizar pela garantia de um nivel relativamente elevado de bem-estar material e de igualdade social, juridica e econômica, além da garantia das diversas expressões da vida social, o que podemos afirmar não ser o caso brasileiro. De tal modo, a necessidade de priorizar a escola como espaço da proteção social, nos leva a compreender que a democracia brasileira não se encontra pautada na igualdade social e de direitos.

Outro ponto a ser destacado é que, conforme destacado por Pochmann (2004, p. 7), a lógica de proteção social, para países como o Brasil, que não pertencem ao centro do capitalismo mundial, deve considerar, inicialmente, essa "condição de pertencimento à periferia econômica, prisioneira do subdesenvolvimento". Para o autor, a sustentação do ciclo de financeirização da riqueza no Brasil perpetua a pobreza e a exclusão social, fazendo do pobre "alvo de mera assistência" (2004, p. 14).

Assim sendo, a focalização presente nessas políticas se consolida como um arremedo de proteção social, uma vez que estão sustentadas sob a óptica neoliberal. Essa proteção está relacionada a dois elementos da nova filantropia discutidos por Ball e Omedo (2013, p. 34), quais sejam: a "filantropia 2.0", aquela que está ligada ao desenvolvimento, indo ao encontro de textos de organismos internacionais, do início da década de 1990, e a "filantropia 3.0" que está associada à "caridade lucrativa". De tal modo, o Estado, em alinhamento a outros setores da sociedade civil, estaria no discurso da proteção social, exercendo essa nova filantropia que lida com a necessidade imediata dos sujeitos sem buscar transformar, efetivamente, a sua realidade e da sociedade no que tange às desigualdades sociais.

Dando continuidade à apresentação das análises propostas neste estudo, serão destacadas aqui as rupturas observadas no PME em relação aos CIACs.

O primeiro elemento a ser destacado em relação a esta questão está relacionado à construção de espaço físico para a implementação das políticas. No caso do Programa Minha Gente, foi prevista a construção de equipamentos públicos para o atendimento aos estudantes. Já no caso 
do PME, era evocada a perspectiva de que as escolas deveriam se articular com seu entorno para garantirem a oferta do tempo integral. Essa ação, conforme apontado por Cavaliere (2007) está amparada na perspectiva das Cidades Educadoras, que considera todos os espaços da cidade como potenciais educativos.

O que se destaca nesse primeiro elemento apresentado, é a inexistência de investimento financeiro por parte dos recursos destinados ao PME, para a construção de novas escolas que pudessem atender aos estudantes contemplados no tempo integral, por meio do referido programa. Para Leclerc e Moll (2012), o programa problematiza a forma como a escola se organiza em relação ao seu espaço físico e como se articula com o seu entorno. Entretanto, há que se considerar a história recente e atual de precarização dos espaços escolares Brasil afora, bem como as vulnerabilidades territoriais, caracterizadas pela precariedade de serviços coletivos e de investimentos públicos.

O que se considera aqui não é a necessidade de uma institucionalização das crianças e dos adolescentes, de modo que esses tenham que ficar somente no espaço escolar. As experiências e vivencias em outros locais são parte importante do processo educacional. A questão é que a articulação com outros locais deve ocorrer como uma proposta pedagógica e não da necessidade em decorrência da ausência do espaço físico.

O segundo elemento a ser destacado - o espaço de permanência dos estudantes para serem atendidos em tempo integral - está, nesta análise, diretamente relacionado ao elemento anteriormente apontado. Se nos CIACs, considerando a existência de um espaço físico, os estudantes eram atendidos dentro do espaço escolar, no PME, o atendimento em tempo integral está sob a responsabilidade da escola, sem necessariamente ocorrer em seu espaço. Levando em consideração o PME, como seria possivel atender aos estudantes nas escolas, se não havia uma proposta de ampliação dos seus espaços? Os discursos em torno da utilização dos diversos espaços educativos do território estariam relacionados a uma perspectiva de potencializar e valorizar a localidade, ou se constituíram como um recurso discursivo para encobrir a ausência de investimentos em infraestrutura para a consecução do programa?

A ideia da escola se articular com outros espaços para atender aos seus estudantes pode sinalizar para o fortalecimento dessa instituição com o seu entorno, em uma possibilidade de fortalecimento das ações intersetoriais naquele território. Entretanto, analisando mais a fundo, podemos compreender esse movimento como uma "ampliação para menos" das funções da escola, como aponta Algebaile (2009), uma vez que essa instituição passa a se ocupar de uma pseudo proteção social e, ainda, buscar espaços físicos para compensar a sua ausência na ampliação da jornada escolar dos estudantes.

\section{Considerações finais}

O Brasil, assim como os países latino-americanos, está exposto, em razão de sua posição na economia mundial, a lugares subalternizados no cenário econômico mundial. Essa posição é reforçada pela lógica neoliberal, que reitera as desigualdades sociais. No que tange às politicas educacionais, isso pode ser observado pela sua descontinuidade e, ainda, pelo papel que os organismos internacionais ocupam nas recomendações (e no financiamento) dessas politicas.

No âmbito das políticas de ampliação da jornada escolar, na perspectiva do tempo integral, a influência internacional fica clara quando da focalização em determinados sujeitos, na perspectiva da proteção social e como estratégia para melhorar a qualidade da educação, aferida por avaliações em larga escala.

Destaca-se entre as duas políticas analisadas as permanências associadas à proteção social e à participação de toda a sociedade nesses projetos. Nas rupturas, observa-se a ausência de investimentos para a construção de escolas, em relação ao PME, bem como a lógica de atendimento dos estudantes, se na escola ou no entorno dela.

Reforça-se que ambas as políticas se configuram no rol de ações sob a óptica neoliberal 
que, essencialmente, não vão de encontro ao fortalecimento de uma política de Estado efetivamente para todos.

\section{Referências}

ABICALIL, C. A. O regime de colaboração na promoção da educação. In: Conferência Nacional de Educação, Cultura e Desporto, 2001, Brasilia, DF. Anais[...] Brasilia, DF: Câmara dos Deputados, 2001.

ALGEBAILE, E. Escola pública e pobreza no Brasil: a ampliação para menos. Rio de Janeiro: Lamparina, Faperj, 2009

BALL, Stephen; OLMEDO, Antonio. A Nova Filantropia, o Capitalismo Social e as Redes de Politicas Globais em Educação. In: PERONI, V. M. V. Redefinições das fronteiras entre o público e o privado: implicações para a democratização da educação. Brasilia: Liber Livro, p. 33-47, 2013.

BANCO MUNDIAL. Education Sector Strategy. Washington, D.C.: World Bank, 1999.

BORON, A. A. El Estado y lãs "reformas del Estado orientadas al mercado". Los "desempeños" de la democracia em América Latina. In: KRAWCZYK N. R.; WANDERLEY, L. E. América Latina: Estado e reformas numa perspectiva comparada. São Paulo: Cortez, 2003

BRASIL. Decreto de 14 de maio de 1991. Dispõe sobre o Projeto Minha Gente e dá outras providências. Diário Oficial da União, Brasília, DF, 1991

BRASIL. Decreto $n^{\circ} 7.083$, de. Portaria $n^{\circ} 12$, de 27 de janeiro de 2010. Dispõe sobre o Programa Mais Educação. Diário Oficial da União, Brasília, DF, 2010.

BRASIL. Ministério da Educação. Secretaria de Educação Básica. Diretoria de Currículo e Educação Integral. Manual Operacional da Educação Integral, no exercício de 2010. Brasilia, DF, 2010.

BRASIL. Portaria Normativa Interministerial $n^{\circ} 17$, de 24 de abril de 2007. Institui o Programa Mais Educação, que visa fomentar a educação integral de crianças, adolescentes e jovens, por meio do apoio a atividades socioeducativas no contraturno escolar Diário Oficial da União, Brasilia, DF, 2007

BRASIL. Projeto Minha Gente: informações básicas sobre o projeto. Brasilia: Instituto Nacional de Pesquisas e Estudos Educacionais, 1992.

CANDAU, V. M. Reformas Educacionais hoje na América Latina. In: MOREIRA, A. F. B. (org.). Curriculo: politicas e práticas. 13. ed. Campinas, SP: Papirus, 2013.

CAVALIERE, A. M. Tempo de escola e qualidade na educação pública. Educ. Soc., Campinas, v. 28, n. 100 - Especial, p. 1015-1035, out. 2007. https://doi org/10.1590/S0101-73302007000300018

CAVALIERE, A. M. Escolas de tempo integral versus alunos em tempo integral. Em Aberto, Brasilia, v. 22, n. 80, p. 51-64, 2009.
CELLARD, André. A análise documental. In: POUPART, Jean. A pesquisa qualitativa: enfoques epistemológicos e metodológicos. Petrópolis: Vozes, 2008.

CEPAL-UNESCO. Educacion y conocimineto: eje de la transformacion productiva com equidade. UNESCO, 1996.

COELHO, L. M. C. C. Alunos no Ensino Fundamental, ampliação da jornada escolar e Educação Integral. Educar em Revista, Curitiba, Brasil, n. 45, p. 7389, jul./set. 2012. https://doi.org/10.1590/S010440602012000300006 .

COUTINHO, L. N. Cidadania, democracia e educação. Revista Ideias, São Paulo, n. 24, 1994

DINIZ JUNIOR, C. A. Comitês territoriais de Educação Integral: das ideias ao texto. 2016. 143f. Dissertação (Mestrado em Educação) - Universidade Federal do Estado do Rio de Janeiro, Rio de Janeiro, 2017.

FANFANI, E. T. (coord.). Estado del arte: escolaridade primaria y jornada escolar em el contexto internacional - estudio de casos en Europa y América Latina. UNESCO, 2010

FREITAS, L. C. (Prefácio). In: TODOS PELA EDUCAĊ̃̃? Como os empresários estão determinando a politica educacional brasileira. Rio de Janeiro: Lamparina, 2016.

GADOTTI, M. Educação Integral no Brasil: inovações em processo. São Paulo: Editora e Livraria Instituto Paulo Freire, 2009

GENTILI, P. Neoliberalismo e educação: manual do usuário. In: SILVA, T. T.; GENTILI, P. (org.). Escola S.A. quem ganha e quem perde no mercado educacional do neoliberalismo. Brasilia, DF: CNTE, 1996.

LECLERC, G. F. E.; MOLL, J. Programa Mais Educação: avanços e desafios para uma estratégia indutora da Educação Integral e em tempo integral. Educar em Revista, Curitiba, n. 45, jul./set. 2012. https://doi. org/10.1590/S0104-40602012000300007.

LIBÂNEO, J. C. Politicas educacionais no Brasil: desfiguramento da escola e do conhecimento escolar. Cadernos de Pesquisa, v. 46, n. 159, p. 38-62, jan./ mar, 2016. https://doi.org/10.1590/198053143572.

MARTINS, E. M. Todos pela Educação? Como os empresários estão determinando a política educacional brasileira. Rio de Janeiro: Lamparina, 2016

MENEZES, J. S. S. Educação integral e tempo integral na educação básica: da LDB ao PDE. In: SIMPÓSIO INTERNACIONAL: O ESTADO E AS POLITICAS EDUCACIONAIS NO TEMPO PRESENTE, 4., 2008, Uberlândia. Anais do IV Simpósio Internacional: - Estado e as políticas educacionais. Uberlândia: Digiteca, 2008.

PENA, R. L. Os "CIEPs de Collor": uma análise sobre o Projeto Minha Gente. 2015. 89 f. Dissertação (Mestrado em Educação) - Universidade Federal Fluminense, Faculdade de Educação, 2015. 
POCHMANN, M. Proteção Social na periferia do capitalismo: considerações sobre o Brasil. São Paulo em Perspectiva, São Paulo, v. 18, n. 2, 2004. https://doi. org/10.1590/S0102-88392004000200002.

SHIROMA, E. O.; MORAES, M. C. M.; EVANGELISTA, O. Política Educacional. 4. ed. Rio de Janeiro: Lamparina, 2011.

SILVA, A. G. A. Políticas de ensino integral na América Latina. Revista Educação em Questão, Natal, v. 55, n. 46, p. 84-105, out./dez. 2017. https://doi. org/10.21680/1981-1802.2017V55n46ID13293.

SOBRINHO, J. A.; PARENTE, M. M. A. CAIC: solução ou problema? Instituto de Pesquisa Econômica Aplicada, 1995.

UNESCO. Declaração de Dakar. Educação para todos: texto adotado pela Cúpula Mundial de Educação. Dakar, 2000.

\section{UNESCO. Declaração Mundial sobre Educação}

para Todos: satisfação das necessidades básicas de aprendizagem. UNESCO: Jomtien, 1990

\section{Carlos Antonio Diniz Junior}

Doutorando e Mestre em Educação pela Universidade Federal do Estado do Rio de Janeiro (Unirio, Rio de Janeiro, RJ, Brasil), bolsista Capes, professor do Centro Universitário Celso Lisboa no Rio de Janeiro, RJ, Brasil.

\section{Endereço para correspondência}

Carlos Antonio Diniz Junior

Universidade Federal do Estado do Rio de Janeiro

Av. Pasteur, 458, Prédio do $\mathrm{CCH}$ - térreo

Urca, 22290-240

Rio de Janeiro, RJ, Brasil 